\title{
Transient Characteristics Analysis of DFIG during Power Grid Fault and Crowbar Resistance Adaptive Tuning
}

\author{
Y.J. Gu, Y. Nie, Y.J. Jiao, Y.Q. Xu \\ Department of electric power engineering \\ North China Electric Power University \\ Baoding, Hebei, China
}

\begin{abstract}
The purpose of this paper is to improve low voltage ride through (LVRT) capability of doubly fed induction generator (DFIG).First, this paper gives expressions of the stator flux and rotor current during the grid fault occurrence and clearing by solving the mathematical model of DFIG. The results of simulation conducted on a $1.5 \mathrm{MW}$ DFIG in the PSCAD/EMTDC verified the correctness of the derivation. Through qualitative analysis of stator flux expression, different fault durations will lead to the difference of transient during fault clearing and ignoring the process of fault clearing will lead to excessive crowbar resistance. Therefore, this paper optimizes the Crowbar resistance by considering both the process of grid fault and fault clearing, and then presents a Crowbar resistance adaptive setting principle based on Crowbar structure with parallel resistor. Simulation confirms this method can improve LVRT of wind farms.
\end{abstract}

Keywords-doubly fed induction generator (DFIG); transient characteristics; low voltage ride through (LVRT); Crowbar circuit; adaptive tuning

\section{INTRODUCTION}

DFIG has two converters with small capacity and its active and reactive power can be adjusted independently, so it is widely used in the world [1-2]. But the DFIG stator is directly connected to the grid, so it's vulnerable to the impact of system faults. The transient characteristics of DFIG are complex, and control ability of the small capacity converters is limited, making it more difficult to realize LVRT [3-4]. When a serious fault occurs, it's needed to add hardware device for low voltage ride through, among which Crowbar protection is most widely used. Accurate analysis and calculation of DFIG transient process is the premise and key to the design of Crowbar protection scheme.

A lot of papers analyze and calculates the transient process of DFIG. When grid voltage sags, the impact of transient flux on rotor open circuit voltage was analyzed in [5]; [6] derived DFIG rotor current expression under grid faults, but only under the converter controlled conditions; [7] analyzed the impact of crowbar protection action time on DFIG short circuit current, and acquired the short circuit current expressions; [8] made use of mathematical analytical method to analyze the electromagnetic transient process of DFIG, and gave the expressions of rotor flux and current; [9] precisely deduced the expressions of stator, rotor flux and voltage, on the basis of which putting forward a new design method to optimize the parameters of new Crowbar circuit structure. [10-13] calculated the maximum estimated value of DFIG short-circuit current, and then gave the constraints optimization of Crowbar resistance.

The references above mostly studied the DFIG transient process during the period of the fault, with the result that LVRT strategy (such as the Crowbar resistance selection) was not reasonable. Aiming at solving the problem, this paper studies the whole transient process of fault occurrence and clearing of DFIG, derives the expressions of the stator and rotor current, simulation verifies the correctness of deduction. At last, a Crowbar resistance adaptive tuning principle is proposed to improve the LVRT ability of DFIG.

\section{ANALYSIS OF DFIG TRANSIENT CHARACTERISTICS}

\section{A. Analysis and Calculation of the Stator Flux Linkage}

According to the motor convention, in the two-phase stationary coordinate system, the DFIG voltage and flux linkage equations are[5]:

$$
\begin{gathered}
\mathbf{u}_{\mathrm{s}}=\mathrm{R}_{\mathrm{s}}+\mathrm{p} \boldsymbol{\Psi}_{\mathrm{s}} \\
\mathbf{u}_{\mathrm{r}}=\mathrm{R}_{\mathrm{r}} \mathbf{i}_{\mathrm{r}}+\mathrm{p} \boldsymbol{\Psi}_{\mathrm{r}}-\mathrm{j} \omega \boldsymbol{\Psi}_{\mathrm{r}} \\
\boldsymbol{\Psi}_{\mathrm{s}}=\mathrm{L}_{\mathrm{s}} \mathbf{i}_{\mathrm{s}}+\mathrm{L}_{\mathrm{m}} \mathbf{i}_{\mathrm{r}} \\
\boldsymbol{\Psi}_{\mathrm{r}}=\mathrm{L}_{\mathrm{r}} \mathbf{i}_{\mathrm{r}}+\mathrm{L}_{\mathrm{m}} \mathbf{i}_{\mathrm{s}}
\end{gathered}
$$

Where $\boldsymbol{u}, \boldsymbol{i}$ and $\boldsymbol{\psi}$ are voltage, current and flux vector, $R$ and $L$ are resistances and inductance, subscripts $s, r$ represent the stator and the rotor respectively, $p$ is differential operator.

The grid three-phase symmetrical short circuit in 0 s, voltage sag depth is $\mathrm{k}, t_{l}$ is grid voltage recovering time. Stator voltage can be expressed as:

$$
\mathrm{u}_{\mathrm{s}}=\left\{\begin{array}{cc}
\mathrm{U}_{\mathrm{sm}} \mathrm{e}^{\mathrm{j} \omega \mathrm{t}} & \mathrm{t}<0, t>\mathrm{t}_{1} \\
\mathrm{kU}_{\mathrm{sm}} \mathrm{e}^{\mathrm{j} \omega \mathrm{t}} & 0 \leq \mathrm{t} \leq \mathrm{t}_{1}
\end{array}\right.
$$

The voltage amplitude is synchronous electric angular velocity. Ignoring the stator resistance, equation 5 into equation 1, stator flux can be solved as: 
$\Psi_{s}=\left\{\begin{array}{cc}\frac{k U_{s m}}{j \omega_{s}} e^{j \omega_{s} t}+\frac{(1-k) U_{s m}}{j \omega_{s}} e^{-T_{s t}} & 0 \leq t \leq t_{1} \\ \frac{U_{s m}}{i \omega_{c}} e^{j \omega_{s} t}-\frac{(1-k) U_{s m}}{i \omega_{c}}\left(e^{j \omega_{s} t_{1}}-e^{-T_{S} t_{1}}\right) e^{-T_{S}\left(t-t_{1}\right)} t>t_{1}\end{array}\right.$

Expression (6) shows that both the fault occurrence and clearance will cause transient changes of stator flux linkage. The stator flux linkage contains synchronous rotating AC component and the DC component which attenuates by time constant Ts. The amplitude of stator flux linkage oscillation is related to the voltage sag degree k; stator flux linkage goes in the same rules of vibration attenuation in the fault clearance stage, but the amplitude of the oscillation is not only associated with $\mathrm{k}$, but the fault clearing time $\mathrm{t} 1$, so extracts feature component in (6):

$$
\psi_{s n}=\left[\frac{(1-k) U_{s m}}{j \omega_{s}}\left(e^{j \omega_{s} t_{1}}-e^{-T_{s} t_{1}}\right)\right] e^{-T_{s}\left(t-t_{1}\right)}
$$

When $t=t_{l}$, obtain the maximum value:

$$
e_{r}=\left\{\begin{array}{lr}
\frac{L_{m}}{L_{s}} s k U_{s m} e^{j \omega_{s} t}-\frac{L_{m}}{L_{s}}(1-s)(1-k) U_{s m} e^{-T_{s} t} & 0 \leq t \leq t_{1} \\
\frac{L_{m}}{L_{s}} s U_{s m} e^{j \omega_{s} t}+\frac{L_{m}}{L_{s}}(1-s)(1-k) U_{s m}\left(e^{j \omega_{s} t_{1}}-e^{-T_{s} t_{1}}\right) e^{-T_{s}\left(t-t_{1}\right) t \geq t_{1}}
\end{array}\right.
$$

Simplification of expression 12 is:

Where: $\mathrm{s}$ is slip. When Crowbar is connected, $\mathbf{u}_{\mathrm{r}}=-\mathbf{R}_{\mathbf{c}} \mathrm{i}_{\mathrm{r}}$, where is Crowbar.

Expression (11) can be transformed into:

$$
i_{r}=-\frac{A}{j \omega_{s} \sigma L_{r}+F} e^{j \omega_{s} t}+\frac{B}{\sigma L_{r} T_{s}-F} e^{-T_{s} t}+C_{1} e^{-\frac{F}{\sigma L_{r}} t}
$$

$$
\begin{gathered}
\sigma L_{r} p_{r}+\left(R_{r}+R_{c}-j \omega_{r} \sigma L_{r}\right) i_{r}=-e_{r} \quad(12) \quad \text { Where: } F=R_{r}+R_{c}-j \omega_{r} \sigma L_{r}, \\
A=\left\{\begin{array}{ll}
\frac{L_{m}}{L_{s}} s k U_{s m} 0 \leq t \leq t_{1} \\
\frac{L_{m}}{L_{s}} s U_{s m} \quad t \geq t_{1}
\end{array}, B= \begin{cases}-\frac{L_{m}}{L_{s}}(1-s)(1-k) U_{s m} & 0 \leq t \leq t_{1} \\
\frac{L_{m}}{L_{s}}(1-s)(1-k) U_{s m}\left(e^{j \omega_{s} t_{1}}-e^{-T_{s} t_{1}}\right) t \geq t_{1}\end{cases} \right.
\end{gathered}
$$

From expression (13), rotor current consists of three components: AC steady-state component, DC attenuation component and rotor speed frequency attenuation component, which attenuates by rotor time constant, which is related to DFIG parameters, rotor speed and Crowbar resistance.C1can be obtained from rotor current initial values at each stage. In the steady state, DFIG adopts the stator flux oriented vector control, so rotor current in the steady state are [2]:

$$
\left\{\begin{array}{c}
\mathrm{i}_{\mathrm{rq}}=-\frac{2 \mathrm{P}_{\mathrm{s}}}{3 \mathrm{U}_{\mathrm{s} 0}} \\
\mathrm{i}_{\mathrm{rd}}=\frac{\mathrm{U}_{\mathrm{s} 0}}{\omega_{\mathrm{s}} \mathrm{L}_{\mathrm{s}}}-\frac{2 \mathrm{Q}_{\mathrm{s}}}{3 \mathrm{U}_{\mathrm{s} 0}}
\end{array}\right.
$$

Where: $P_{S}$ and $Q_{S}$ are DFIG active power, reactive power, the subscript $\mathrm{d}$, $\mathrm{q}$ represent $\mathrm{d}$, $\mathrm{q}$ components in $\mathrm{d}$ and $\mathrm{q}$ coordinates system. In the steady state, the DFIG active power, reactive power can be calculated according to the given value of rotor current. Switching expression (15)to the two-phase stationary coordinate system:

$$
i_{r}=\left(i_{r d}+j i_{r q}\right) e^{j \omega_{s} t}
$$

When $\mathrm{t}=0, \mathrm{i}_{\mathrm{r}}(0)=\mathrm{i}_{\mathrm{rd}}+\mathrm{ji} \mathrm{i}_{\mathrm{rq}}$, so $\mathrm{C}_{1}=\mathrm{i}_{\mathrm{r}}(0)+\frac{\mathrm{A}}{\mathrm{j} \omega_{\mathrm{S}} \sigma \mathrm{L}_{\mathrm{r}}+\mathrm{F}}-$ $\frac{\mathrm{B}}{\sigma \mathrm{L}_{\mathrm{r}} \mathrm{T}_{\mathrm{s}}-\mathrm{F}}$, then the rotor current expression can be obtained. Rotor current values can be obtained as DFIG parameters and fault data substitute into expression (14).

\section{SIMULATION AND VERIFICATION}

To verify the above theory is correct, in PSCAD/EMTDC, on the grid under grid connected three-phase symmetrical fault 1.5MW DFIG the simulation, parameters of unit reference [16]. Before fault the speed of generator rotor is $1.2 \mathrm{pu}$, generator full load operation, we suppose wind speed constant during the period of fault.

In the simulation, power system fault at $0.2 \mathrm{~s}$, the terminal voltage symmetry fell to $0.2 \mathrm{pu}, \mathrm{R}_{\mathrm{c}}=0.2 \Omega$, Crowbar protection act when failure occurs, fault durations $0.09 \mathrm{~s}$. The rotor current waveforms are compared in Figure 1 and Figure 2 . The dotted line is the simulation results and the solid line is the calculated results.

From Figure 1 and Figure 2, the rotor current rotor current maximum value after fault clearance is far greater than the time of fault happening when fault duration is very short 
$(0.09 \mathrm{~s})$. Stator flux is not decayed to stable before the fault is cleared while fault is short, if the fault duration is odd times frequency half cycle, amplitude of stator flux oscillation will be greater than the time of fault at fault clearing time, the rotor current will be far greater than the moment of rotor current fault occurs.
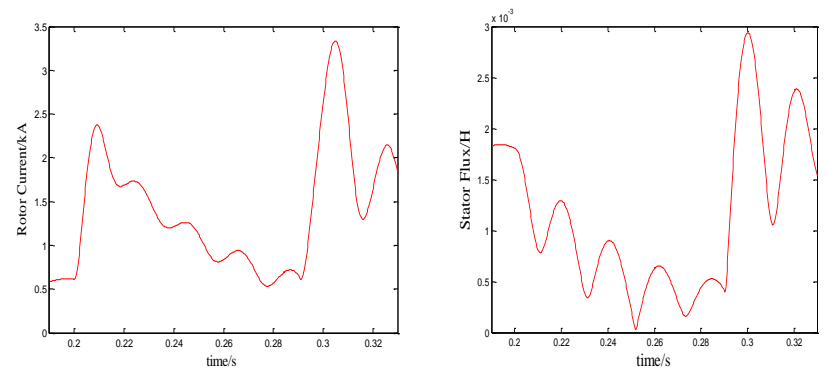

FIGURE I - II .COMPARISON WAVEFORMS OF ROTOR CURRENT AMPLITUDE WHEN FAULT DURATION ARE 0.09S.

\section{OPTIMIZATION OF CROWBAR RESISTANCE}

The main purpose of Crowbar protection is protecting the generator and converter not affected by the rotor over voltage and over current during fault time, to achieve two effects, the Crowbar resistance selection constraint conditions is:

$$
\mathrm{R}_{\mathrm{c}} \leq \mathrm{U}_{\mathrm{dc} \_ \text {lim }} / \mathrm{I}_{\mathrm{r}_{-} \max }
$$

The analysis in this paper shows that at a certain time, the rotor current at the fault clearing stage is much larger than that at the fault occurrence stage. Therefore, this paper adopts a new Crowbar structure with parallel resistor (as shown in Figure 3), and then proposes corresponding Crowbar resistance adaptive tuning principle as follows.

$$
\left\{\begin{array}{l}
\mathrm{R}_{\mathrm{c}} \leq \mathrm{U}_{\mathrm{dc} \text { lim }} / \mathrm{I}_{\mathrm{r}_{-} \max 1} \\
\mathrm{R}_{\mathrm{c}}^{\prime} \leq \mathrm{U}_{\mathrm{dc} \text { _lim }} / \mathrm{I}_{\mathrm{r}_{-} \max 2}
\end{array}\right.
$$

Where: $R_{c}, R_{c}^{\prime}$ are the crowbar resistors settings at both fault occurrence and clearing stage, $\mathrm{I}_{\mathrm{r}_{-} \max 1}, \mathrm{I}_{\mathrm{r}_{-} \max 2}$ are the maximum values of rotor current at both fault occurrence and clearing stage, which can be calculated by the 1.2 quarter of theoretical, the Crowbar resistance values obtained are simulated respectively. It can be seen from Figure 4 that according to traditional methods DC bus voltage exceeds the allowable range at the fault clearing stage, indicating that Crowbar resistance setting is improper; in contrast the use of adaptive tuning principle can keep DC bus voltage in the allowable range. Therefore scheme proposed in this paper is more reasonable.

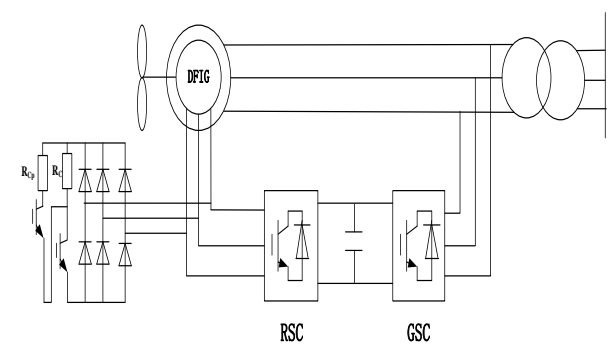

FIGURE III. .CROWBAR WITH PARALLEL RESISTOR.

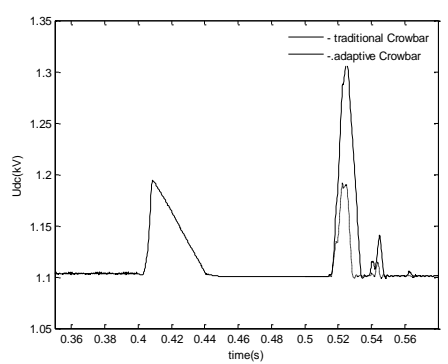

FIGURE IV. .COMPARISONS OF DC VOLTAGE.

\section{CONCLUSION}

On the basis of DFIG mathematical model, the transient characteristics of DFIG are analyzed and derived during the whole fault period, the simulation analysis verifies the correctness of the theoretical analysis, accordingly a novel selection and control scheme of Crowbar resistance is proposed. Therefore, some useful conclusions are obtained as follows:

1) Rotor current derived in this paper has higher calculation accuracy.

2) When fault duration is odd times to half power cycle after fault, the stator flux oscillations, the rotor over voltage and over current is more serious; when fault duration is integer times to power cycle, DFIG quickly restore stability after fault is cleared, causing smaller transient impact, so the rotor converter can regain control unit quickly.

3) This paper comprehensively considers the whole stage of both in fault occurrence and clearing process, and Crowbar resistance adaptive tuning principle is proposed accordingly, which can effectively improve the ability of LVRT.

\section{REFERENCES}

[1] He Yikang, Hu Jiabing. Several Hot-spot Issues Associated With the Grid-connected Operations of Wind-turbine Driven Doubly Fed Induction Generators [J]. Proceedings of the CSEE, 2012, 32(27): 140-146.

[2] Lu Kai,Zhang Yao, Ni Wei dong,et al. Research of the improved control strategy for a double-fed generation system under grid voltage dip [J]. Power System Protection and Control, 2012, 40(11): 106-111.

[3] Wang Wei, Sun Mingdong, Zhu Xiaodong. Analysis on the low voltage ride through of DFIG [J]. Automation of Electric Power Systems, 2007, 31 (23): 84-89(in Chinese).

[4] Lopez J,Sanchis P,Roboam X,et al. Dynamic behavior of the doubly fed induction generator during three-phase voltage dips[J]. IEEE Transactions on Energy Conversion, 2007, 22(3): 709-717.

[5] Xiong Xiaofu,Ou yang Jinxin. Analysis and calculation of rotor currents for doubly-fed induction generators under short circuits in power grids[J]. Proceedings of the CSEE, 2012, 32(28): 114-121(in Chinese).

[6] Zheng Tao, Wei Zhangpeng, Chi Yongning, et al. Short-circuit current characteristic of doubly fed induction generator considering crowbar protection insertion time [J]. Automation of Electric Power Systems, 2014, 38(5): 25-30.

[7] Yang Shuying, Sun Dengyue, Chen Liuwei, et al. Study on electromagnetic transition of DFIG-based wind turbines under grid fault based on analytical method [J]. Proceedings of the CSEE, 2013, 33: 13-20.

[8] Meng Yongqing, Weng Yu, Wang Xifan,et al. Accurate calculation of DFIG transient performance and parameters optimization of crowbar circuit[J]. Automation of Electric Power Systems, 2014, 38(8): 23-29. 
[9] Zhu Xiaodong,Shi Lei,Chen Ning,et al. An analysis on low voltage ride through of wind turbine driven doubly fed induction generator with different resistances and quitting time of crowbar [J]. Automation of Electric Power Systems, 2010, 34(18): 84-89(in Chinese).

[10] MaHaomiao, Gao Yong, Yang Yuan, et al. Fuzzy optimization of crowbar resistances for low-voltage ride through of doubly-fed induction generators [J]. Proceedings of the CSEE, 2012, 32(34): 17-23.

[11] Morren J, de Haan S.W.H. Short circuit current of wind turbines with doubly-fed induction generator [J]. IEEE Transactions on Energy Conversion, 2007, 22(1): 174-180.

[12] Pannell G,Atkinson D J, Zahawi B. Minimum-thresh-old crowbar for a fault-ride-through grid-code-compliant DFIG wind turbine[J]. IEEE Transactions on Energy Conversion,2010, 25(3): 750-759.

[13] Jia Junchuan, Liu Jin, Zhang Yigong. Dynamic characteristics of stator flux of doubly-fed induction generator during grid voltage fault [J]. Proceedings of the CSEE,2011, 31(3): 90-96(in Chinese). 